the treatment programs and growing numbers of inmates now seek treatment."

But demand continues to skyrocket and far outstrips treatment capacity.

In BC, "I now have almost 80 patients in treatment, with many more on my waiting list," says Farley.

Compounding the problem is that the federal government seems to find harm reduction programs in prisons to be anathema, the physicians say. CSC's "rejection of strategies such as needle exchange and safer tattooing programs in prisons is a well-known public health menace," Ford notes. "But the vastly increasing cost of HIV treatment in prisons proves that CSC's policies are financially irresponsible as well."

Farley says treating patients who became re-infected while in prison has become a nation-wide phenomenon. "We are now seeing many people being treated for hepatitis $\mathrm{C}$ at significant public expense and then getting reinfected because of the government's rejection of basic harm reduction measures. The financial cost of hepatitis $\mathrm{C}$ in the prisons is becoming horrific."

Both physicians abhor the federal government's dismantling of a pilot project aimed at promoting safer tattooing within six federal prisons in 2006. An estimated $45 \%$ of inmates receive unsterile tattoos (www.cmaj.ca/lookup /doi/10.1503/cmaj.1070017), while an estimated $25 \%$ of inmates use needles to inject illegal substances (QJM 2000; 93:113-19).

Some of the latter are first-time users, Farley says. "I usually ask my patients where they started injecting drugs and between 5 and 10 percent say it was while in prison."

Harm reduction programs in federal prisons are now essentially limited to such "half-measures" as providing bleach to sterilize needles, Farley says. Yet, "bleach is known to be an ineffective way of preventing disease transmission."

Failure to implement adequate harm reduction measures, lack of adequate access to care and lack of consistency between federal institutions lay at the heart of a failing grade that CSC received in 2011 from the Canadian Coalition of Organizations Responding to Hepatitis B and $\mathrm{C}$ (www.canadianhepatitiscoalition .ca/wp-content/uploads/2011/07/2011 -Hepatitis-Strategy-Report-Card.pdf)

"We gave them an $\mathrm{F}$ because we have to believe that CSC is fully aware that people engage in risky behaviour in prison," says coalition spokeswoman Deb Shmitz. "It's a denial of the reality not to provide full harm reduction. Just as there is a duty to treat inmates with hepatitis, there is a similar duty to do harm reduction as well. And that includes distributing needles and collecting used needles."

Shmitz argues CSC should be held partially responsible for the rising rate of hepatitis $\mathrm{C}$ infection in non-inmate population groups as it's fully aware inmates typically join the ranks of intravenous drug users and the homeless when they are released into the general population. "The public needs to know that failure to prevent hepatitis transmission inflicts a severe long-term financial burden on public health systems."

For its part, CSC argues that its approach is working. The hepatitis $\mathrm{C}$ prevalence rate appears to be "levelling" at about $30 \%$, says Dr. Linda Panaro, public health medical advisor for CSC, ascribing that to the efficacy of treatment programs and harm reduction measures such as bleach provision. "The harm reductions materials we distribute are having an effect."

Panaro adds that the sevenfold increase in hepatitis $C$ treatment costs within prisons is the product of more rigorous cost accounting measures but acknowledges those costs may skyrocket if the new therapies are approved for use. - Paul Christopher Webster, Toronto, Ont.

CMAJ 2012. DOI:10.1503/cmaj.109-4191

\section{Medical ink}

I f your spouse's initials are "D.N.R.," you should probably think twice before tattooing them on your chest. Then again, if your end-of-life plans include a do-not-resuscitate order, maybe it's not such a bad idea after all.

It appears the tattoo craze has expanded beyond mere aesthetics into medicine. Some people are setting down advance directives on skin in addition to paper. Others are opting for tattoos on their wrists instead of Medic Alert bracelets, favouring ink over jewellery. Though there are advantages to turning your epidermis into a medical record - you can't accidently leave your forearm at home - some health professionals fear that paramedics and emergency physicians might not notice the tattoos, let alone treat them as proper instructions.

"Emergency responders understand the concept of MedicAlert bracelets and they look for them on the wrist. It is possible that some have learned that people are using tattoos but the chances of them looking for it are much less," says Robert Ridge, president and CEO of the Canadian MedicAlert Foundation. "There is no overriding body that governs emergency services in Canada, so when something changes there is no national means to communicate it. Getting every emergency responder to look for something new can be a challenge."
The days of tattoos being associated only with bikers and ex-cons are long gone. Now tattooing is firmly planted in the mainstream. A woman is as likely to have one as a man. There are reality television shows about tattoo artists. Celebrities sport tattoos, including the popular actress Angelina Jolie, who has nearly a dozen. Many professional athletes are covered in more ink than an incontinent squid.

In the United States, $36 \%$ of people in the 18-25 age bracket have a tattoo, and that percentage increases to $40 \%$ for people between the ages of 25 and 40, according to the Pew Research Center in Washington, DC (http://pewresearch .org/databank/dailynumber/?NumberID 
$=237$ ). By contrast, only $10 \%$ of people aged 41-64 have one.

So perhaps it should come as little surprise that some young people with allergies or conditions such as diabetes have no qualms about tattooing that information on their bodies. Some people prefer tattoos because they can't wear jewellery to work (electricians, for example) or because bracelets and necklaces are easily broken and lost during certain sporting activities, such as surfing. Others simply like the look of a tattoo more than jewellery.

Tanyss Christie, a 35-year-old from Chilliwack, British Columbia, got a tattoo last year that declares she has type 1 diabetes. "I have a friend and she got one, too, after she saw mine," says Christie, a mother of two. "I got a little bit different of a design for mine. It's close to a MedicAlert bracelet, but with a little twist [see picture]."

Mike Hillier, a 29-year-old from Mississauga, Ontario, also has type 1 diabetes. He was diagnosed late, at age 24 , and never took to wearing a MedicAlert bracelet, despite being encouraged to do so by his mother and doctor. "I never really wore mine, and I was looking to get another tattoo anyway," says Hillier, a technologist with a satellite broadcasting company. "I wanted it to be something that actually meant something."

How many people have medical tattoos? It's difficult to say. There is no organization keeping track. At very least, it appears to be a trend on the rise, if the extensive gallery on the website for the group Diabetes Advocacy is any indication (www.diabetes advocacy.com/tattoos.htm). Still, despite becoming more popular, medical tattoos are still relatively rare, according to those who work in the ink trade.

"I believe over the years we have maybe done a few of these types of tattoos but it's nothing I would consider by any means common," Jennifer Wiet, general manager of Adrenaline Montreal Tattoos \& Body Piercing, writes in an email. "Personally I feel it's a great idea, especially for people who have a hard time wearing a regular medical alert bracelet. For example I have a friend who had so many medical

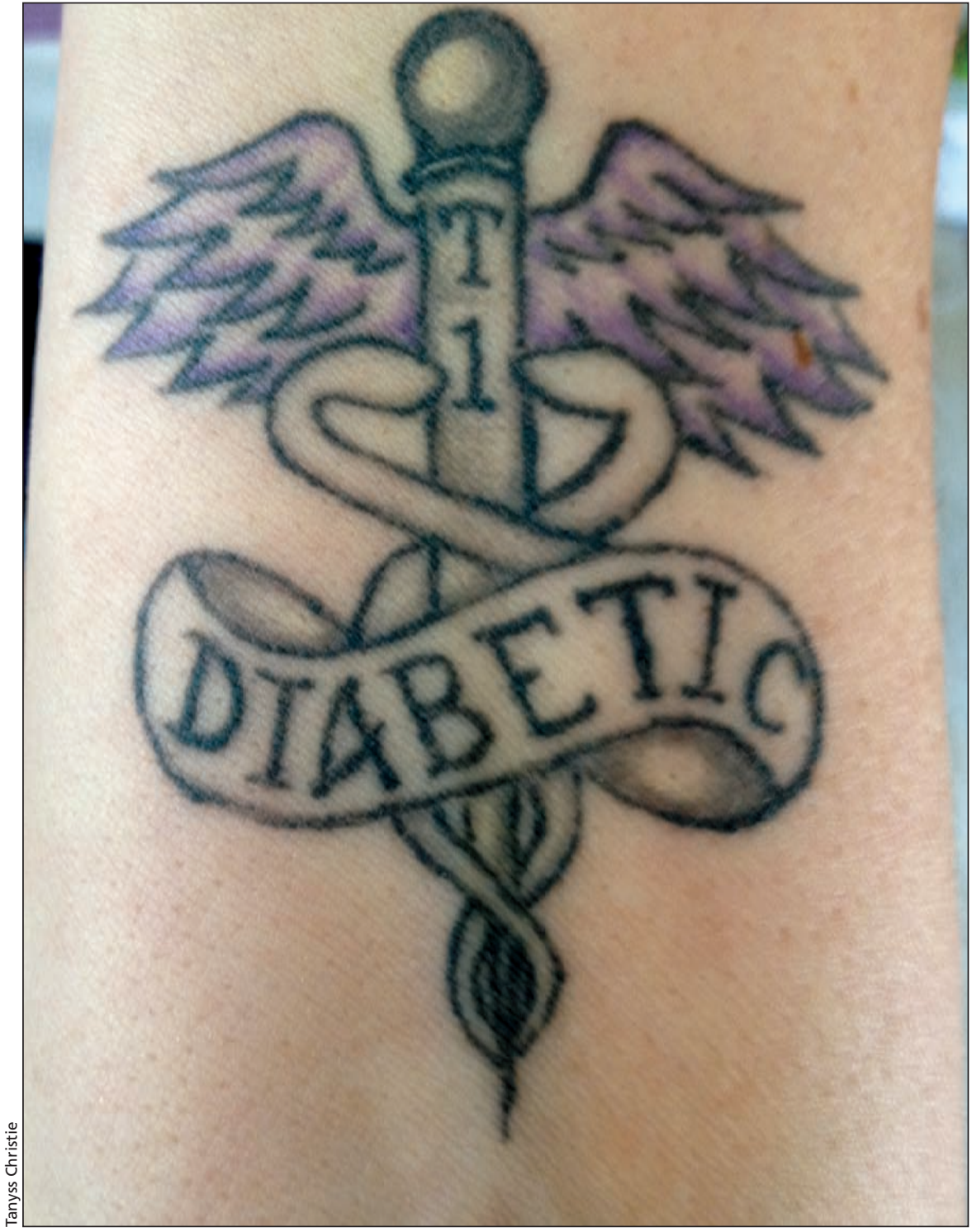

Chilliwack, British Columbia-resident Tanyss Christie designed her medical tattoo to look like "a MedicAlert bracelet, but with a little twist."

'issues' that she requires 2 medic alert bracelets ... not that pretty. Or my mother who is supposed to wear one but is severely allergic to anything that isn't at least $14 \mathrm{k}$ gold. That's an expensive medic alert bracelet!"

Ron Smith, a tattoo artist at Adrenaline, writes in an email that he has done tattoos relaying medical information such as diabetes, heart conditions and high blood pressure but never for a donot-resuscitate order. Mathieu Samson, another Adrenaline tattooist, also indicates that he has done a few MedicAlerttype tattoos.

Nicole Nickerson, of the Sin on Skin Tattoo Studio in Halifax, Nova Scotia, says her shop has done a few medical tattoos over the years, mostly in the MedicAlert style on people's wrists. One client, a soldier who got a tattoo of his blood type, told the studio how his ink helped him on the battlefield. "2 years ago one of our clients while out in a hummer had been hit by a road side bomb and the shrapnel stopped at his tattoo which was his blood type," Nickerson writes in an email. "He called later (jokingly) to say our work was bulletproof as well as great."

Beyond anecdotes, however, there is little information available on medical tattoos. If you conduct a search for data on the topic in medical literature, you might just see digital tumbleweeds roll across your screen. There is one 20- 
year-old paper, though, that presented the case of an aging emergency physician with a symbol indicating "do no defibrillate" on his chest (West J Med 1992;156:309-12). The primary purpose of the tattoo wasn't to offer directions, however, but rather to "make a principled statement about the futility in emergency departments of continuing ACLS [advanced cardiac life support] on patients who do not respond to prehospital resuscitative efforts."

Though relatively rare, it is still time that medical researchers pay more attention to patients who use their bodies to relay important medical information, says Dr. Saleh Aldasouqi, an associate professor of medicine at Michigan State University in East Lansing and the medical director of the Sparrow Diabetes Center.

"This is something of medical relevance. I'm not promoting it. I'm just reporting something that I see on my patients, and I see it as a problem because they are doing it without medical advice," adds Aldasouqi, one of the few academics to ever write about medical tattoos (Am Fam Physician 2011; 83:796). "We are burying our heads in the sand if we are saying this is not occurring and we don't have to worry about it."
The problem with MedicAlert-type tattoos is that, unlike bracelets and necklaces, there are no guidelines regarding their design or location on the body. Indeed, a Google Image search reveals medical tattoos on upper backs, shoulders, wrists, forearms and chests. Some are simple, others elaborate. Some are black, others exploding with colour. There are medical tattoos featuring ribbons, angel wings, snakes, horses, butterflies, skulls, hearts and even the cartoon character Hello Kitty. You see more fonts than in a word processor drop-down menu. A medical tattoo may also be hard to spot on a person with many other tattoos.

"This thing has to be standardized," says Aldasouqi. "We have to at least teach and educate emergency personnel so they become more aware."

As for the legal ramifications of ignoring a do-not-resuscitate tattoo, that is another matter altogether. Those types of tattoos, however, appear to be very rare. There is the odd case that pops up and makes a splash in the popular media. Dr. Ed Friedlander, a 60-year-old pathologist in Kansas City, Missouri, has a "No CPR" tattoo on his chest. Then there is Joy Tomkins, a senior citizen in Norfolk, England, who has "Do Not Resuscitate" tattooed over her heart and the letters "P.T.O." (for "please turn over") on her upper right shoulder.

But emergency personnel are not obligated to follow a tattooed directive, which does not carry the legal weight of a written, properly authenticated donot-resuscitate document, according to Dr. Philip Goscienski, a retired pediatric infectious disease specialist from San Diego, California. Furthermore, it could lead to trouble if a person loses consciousness for a reason unrelated to a medical condition.

"There are a lot of things that can cause someone to collapse that are not cardiac-related," says Goscienski, who has written that "No CPR"-type tattoos are not legal documents and are a waste of good ink (www.nctimes.com /news/opinion/commentary/forum-no -cpr-tattoo-a-waste-of-good-ink/article _ddd86ce4-fb09-5319-9bca-c6ac2363 fda0.html).

"Encountering something like that could slow down the process," he adds. "Paramedics might be reluctant to proceed at the same speed. Maybe they would start searching for an official document. The confusion issue becomes a problem." - Roger Collier, CMAJ

CMAJ 2012. DOI:10.1503/cmaj.109-4204

\section{More news online}

Patients driving alternative medicine boom: With patients seeking more choice and control over their health care options, Canadian health providers and facilities may soon have little choice but to follow the lead of their American counterparts who, increasingly, are offering complementary and alternative medicines in hospitals and other facilities (www.cmaj .ca/lookup/doi/10.1503/cmaj.109-4151). — Jordan Fallis, Ottawa, Ont.

Health care in the caves: Providing health care to indigenous peoples in remote areas is tricky at the best of times. Imagine, though, situations in which some of the patients are living in caves and the primary means of transportation for patients is riding a water buffalo (www.cmaj.ca/lookup /doi/10.1503/cmaj.109-4159). — Tiago Villanueva Gutierrez Arruda Marques MD, Puerto Princesa, Philippines

\section{Screening embryos may lead to} stigma: As advancing genetic screening technologies allow for the detection of subtler mutations, including predisposition to late-onset diseases that can be treated, some ethicists are wondering if creating a list of "serious" conditions to be avoided may have unintended consequences (www.cmaj.ca/lookup /doi/10.1503/cmaj.109-4177). - Roger Collier, CMAJ

Surge in Down syndrome prenatal testing anticipated: A new genetic test that can detect Down syndrome has some physicians concerned that the medical community is not prepared to educate and counsel a potentially huge number of pregnant women facing difficult family planning decisions (www.cmaj.ca/lookup/doi/10.1503/cmaj .109-4170). - Roger Collier, CMAJ

Moos your daddy?: Emerging genetic testing technologies are becoming increasingly popular among animal breeders (www.cmaj.ca/lookup/doi /10.1503/cmaj.109-4181). - Roger Collier, CMAJ

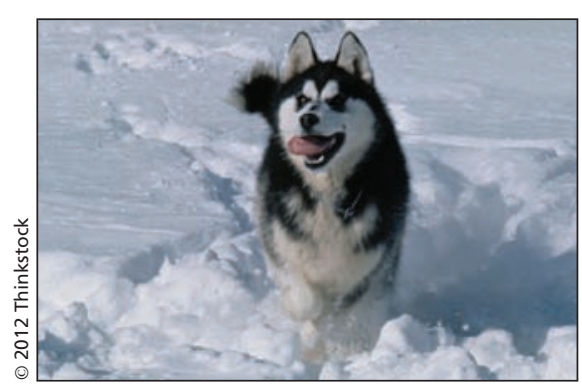

